\title{
FORMULASI RUMAH SAKIT PURI MANDIRI KEDOYA MELALUI PENDEKATAN ANALISIS SWOT UNTUK MENGHADAPI DIBERLAKUKANNYA BPJS KESEHATAN
}

\author{
Nuria Cipta Sari \\ Program Studi Magister Manajemen Universitas Tarumanagara \\ nuria.cipta8@gmail.com \\ Anas Lutfi \\ Program Studi Magister Manajemen Universitas Tarumanagara
}

\begin{abstract}
The purpose of this paper is to analyze the external and internal conditions of the Hospital that can help Puri Mandiri Kedoya Hospital in preparing its strategy plan to face BPJS Health and can provide an overview in developing a comprehensive strategy for Puri Mandiri Kedoya Hospital in making adjustments to the system BPJS Health. The method of writing this work includes the discussion of supporting theories as well as taking necessary data through complementary books, text book or other sources related to this scientific paper. The authors includes data sources from BPJS health book pocket and all related data which has been published, thus the data used is accurate and issue by the government. The results of this study were taken from the analysis of this study were taken from the analysis of both the internal analysis and external analysis of hospitals, by combining the strengths and threats of independent self-sufficiency Puri Mandiri Kedoya Hospital by selecting efficient suppliers for inventory, collaborating with management and medical staff on the use of medicines and health care tools, time-efficient services with the use of integrated medical documentation with computerized systems. Establish partial referral cooperation between surrounding hospitals. Efficiency of Hospital tariff system in preparing cross-subsidy counting to prevent net loss by joining independent Puri mandiri Kedoya Hospital with government program through BPJS Health to be able to survive in service process.
\end{abstract}

Abstrak : Tujuan Penulisan karya ini adalah untuk menganalisa kondisi eksternal dan internal Rumah Sakit yang dapat membantu Rumah Sakit Puri Mandiri Kedoya dalam menyusun rencana strateginya untuk menghadapi BPJS Kesehatan serta dapat memberikan gambaran dalam menyusun strategi komprehensif bagi Rumah Sakit Puri Mandiri Kedoya dalam melakukan penyesuaian terhadap sistem BPJS Kesehatan. Metode penulisan karya ini dengan pembahasan teori pendukung serta mengambil data-data yang diperlukan melalui buku-buku pelengkap, text book atau sumber lainnya yang berhubungan dengan karya tulis ilmiah ini. Penulis juga mencantumkan data-data sumber dari buku saku BPJS Kesehatan serta segala sesuatu yang berkaitan dan telah dipublikasikan sehingga data yang dipakai adalah data akurat yang dikeluarkan oleh pemerintah.. Hasil penelitian ini diambil dari hasil analisa baik dari analisa internal dan analisa eksternal rumah sakit, yaitu dengan menggabungkan antara kekuatan dan ancaman dari rumah sakit puri mandiri kedoya dengan memilih pemasok yang efisien untuk inventory, berkolaborasi dengan manajeman dan staff medis mengenai pemakaian obat-obatan dan alat kesehatan pelayanan, mengefisiensi waktu pelayanan dengan penggunaan dokumentasi medis yang terintegrasi dengan sistem komputerisasi. Menjalin kerjasama rujuk parsial antar RS sekitar. Mengefisiensikan sistem tarif RS dalam menyusun penghitungan subsidi silang untuk mencegah net loss dengan bergabunganya rumah sakit puri mandiri kedoya dengan program pemerintah melalui BPJS Kesehatan rumah sakit tetap dapat bertahan dalam proses pelayanannya. 


\section{Keyword : SWOT Matrix}

\section{PENDAHULUAN}

Berbagai upaya telah pemerintah lakukan dalam rangka meningkatkan kesehatan dan kesejahteraan masyarakat Indonesia khususnya di bidang kesehatan. Berbagai model pembiayaan kesehatan, sejumlah program intervensi teknis di bidang kesehatan, perbaikan sistem dan manajemen telah diperkenalkan pemerintah. Salah satunya yaitu program pemerintah yang tertuang dalam Undang-Undang No 40 Tahun 2004 tentang Sistem Jaminan Sosial Nasional, dan Undang-Undang No 24 Tahun 2011 tentang Badan Penyelenggara Jaminan Sosial (BPJS). Sebagai informasi, hingga 1 Oktober 2017, jumlah peserta JKN-KIS telah mencapai 182.036.673 jiwa. Rumah sakit Puri Mandiri Kedoya merupakan salah satu rumah sakit swasta yang rencananya akan bergabung dengan BPJS di tahun 2019. Penerapan kebijakan program Jaminan Kesehatan Nasional (JKN) melalui Badan Penyelenggara Jaminan Sosial (BPJS) Kesehatan harus betul-betul dimenej dengan baik oleh pihak rumah sakit swasta. Pasalnya, jika salah strategi manajemen rumah sakit swasta yang melayani pasien BPJS bisa rugi hingga miliaran rupiah. Hal itu dikemukakan Direktur RS Permata Cirebon, dr Asad Sp THT-KL terkait kondisi yang harus dihadapi rumah sakit swasta dalam penerapan program BPJS tersebut. Dengan munculnya permasalahan tersebut, maka peneliti bermaksud melakukan penelitian mengenai strategi yang tepat dalam menghadapi peraturan pemerintah BPJS kesehatan pada rumah sakit Puri Mandiri Kedoya agar dapat menyiapkan diri sekaligus mendapatkan keuntungan dengan bertambahnya pasien dari peserta BPJS Kesehatan atau bisa juga menjadi peluang untuk meningkatkan profit rumah sakit untuk menghadapi BPJS kesehatan. Dalam membuat formulasi strategi, rumah sakit harus melalui analisis external dan analisis internal. Analisis ini meliputi analisa strength, weakness, opportunities, dan threat (SWOT). Pada analisis ini poin Strength dan Weakness merupakan bagian internal rumah sakit sedangkan poin Opportunities dan Threat merupakan bagian external rumah sakit. Lalu selanjutnya akan terbentuk suatu rangkaian formulasi strategi yang dapat terukur dan di kontrol secara menyeluruh sehingga rumah sakit tetap dapat berjalan dengan baik.

\section{Tujuan Penelitian}

Tujuan Penulisan karya ini adalah :

- Untuk menganalisa kondisi eksternal dan internal Rumah Sakit yang dapat membantu Rumah Sakit Puri Mandiri Kedoya dalam menyusun rencana strateginya untuk menghadapi BPJS Kesehatan.

- Untuk memberikan gambaran dalam menyusun strategi komprehensif bagi Rumah Sakit Puri Mandiri Kedoya dalam melakukan penyesuaian terhadap sistem BPJS Kesehatan.

\section{Tinjauan Pustaka}

- Strategi Untuk Mencapai Visi dan Misi Perusahaan

Strategi merupakan alat untuk mencapai tujuan perusahaan dalam kaitannya dengan tujuan jangka panjang, program tindak lanjut, serta prioritas alokasi sumber daya menurut Chandler (1962) dalam Rangkuti.

$>$ Perumusan Strategi dan Analisa SWOT

Perumusan strategi atau formulasi strategi merupakan proses penyusunan langkahlangkah kedepan yang dimaksud untuk membangun visi dan misi organisasi, menetapkan tujuan strategi dan keuangan perusahaan. 
- Analisa lingkungan internal dan eksternal

Analisis eksternal

Didalam bukunya Kristianti (2017) membagi kunci kekuatan eksternal menjadi 5 kategori yaitu: Kekuatan ekonomi, Kekuatan social, budaya, demografi, lingkungan, Kekuatan politik, hukum ,dan pemerintah, Kekuatan teknologi, Kekuatan persaingan.

The Industrial Organization (I/O) View

Pandangan ini menyatakan bahwa factor eksternal lebih penting dibandingkan dengan factor internal bagi perusahaan untuk mencapai keunggulan kompetitif (competitive advantage). Menurut Porter dalam Kristianti (2017), persaingan dalam industry dapat meliputi lima kekuatan antara lain :

- Persaingan antara perusahaan yang bersaing

- Potensi masuknya pesaing baru

- Potensi adanya produk substitusi

- Kekuatan tawar-menawar dari pemasok

- Kekuatan tawar menawar dari pembeli

Analisis internal

Dinyatakan oleh Pearce \& Robinson (2013). terdapat beberapa faktor internal kunci yang menjadi fokus analisis internal pada sebagian besar perusahaan. Antara lain : Pemasaran, Keuangan dan Akunting, Produksi, Operasi, Teknik, Personalia, Manajemen Mutu, Sistem Informasi, Organisasi dan Manajemen Umum.

\section{- Analisa SWOT}

Rangkuti (2006) menjelaskan bahwa analisis SWOT adalah identifikasi berbagai faktor secara sistematis untuk merumuskan strategi organisasi. Analisis ini didasarkan pada logika yang dapat memaksimalkan kekuatan (strengths) dan peluang (opportunities), namun secara bersamaan dapat meminimalkan kelemahan (weakness) dan ancaman (threats).

- Pengertian Jaminan Kesehatan

Jaminan Kesehatan adalah jaminan berupa perlindungan kesehatan agar peserta memperoleh manfaat pemeliharaan kesehatan dan perlindungan dalam memenuhi kebutuhan dasar kesehatan yang diberikan kepada setiap orang yang telah membayar iuran atau iurannya dibayar oleh pemerintah (Buku Pegangan Sosilalisasi Jaminan Kesehatan Nasional dalam Sistem Jaminan Sosial Nasional, 2013).

- Kebijakan tarif Jaminan Kesehatan Nasional berdasarkan INA CBGS

Dengan berlakunya sistem Jaminan Kesehatan Nasional (JKN) maka tarif yang diberlakukan sekarang adalah tarif INA-CBGS (Indonesian-Case Based Groups). Tarif INA CBGs adalah besaran pembayaran klaim oleh BPJS Kesehatan kepada fasilitas kesehatan tingkat lanjutan atas paket layanan yang didasarkan kepada pengelompokan diagnosis penyakit.

- Peranan Rumah Sakit Swasta dalam Jaminan Kesehatan

Aida Mus (2013), menyampaikan peranan rumah sakit swasta dalam jaminan kesehatan, meliputi:

$>$ Rumah sakit swasta menjadi bagian integral dalam SKN,

$>$ Kesiapan menghadapi liberalisasi jasa kesehatan termasuk pengembangan health tourism,

> Meningkatkan kontribusi fungsi sosial walaupun rumah sakit swasta tidak $\begin{array}{lllll}\text { diwajibkan } & \text { sebagai } & \text { provider } & \text { jkn } & \end{array}$ 


\section{Kerangka Pemikiran}

Bahwa seluruh rumah sakit milik pemerintah maupun swasta harus menjalankan program pemerintah yaitu Jaminan Kesehatan Nasional (JKN) melalui Badan Pelayanan Jaminan Sosial (BPJS) sesuai dengan program pemerintah yang tertuang dalam UndangUndang No 40 Tahun 2004 tentang Sistem Jaminan Sosial Nasional, dan UndangUndang No 24 Tahun 2011 tentang Badan Penyelenggara Jaminan Sosial (BPJS). Pasalnya, jika salah strategi manajemen rumah sakit swasta yang melayani pasien BPJS bisa rugi hingga miliaran rupiah. Hal itu dikemukakan Direktur RS Permata Cirebon, dr Asad Sp THT-KL terkait kondisi yang harus dihadapi rumah sakit swasta dalam penerapan program BPJS tersebut harus betul-betul dimenej dengan baik oleh pihak rumah sakit swasta. Dengan permasalahan tersebut dibutuhkan strategi yang tepat dalam mengelola sistem BPJS yang masuk ke rumah sakit swasta agar dapat menyiapkan diri, melalui pendekatan analisis SWOT tidak hanya melihat faktor internal yang ada pada rumah sakit dan eksternal dengan menggunakan analisa SWOT sehingga diketahui apa yang menjadi kekuatan dan kelemahan (faktor internal strategis) serta peluang dan ancaman (faktor eksternal strategis) bagi rumah sakit. Dan selanjutnya akan terbentuk suatu rangkaian formulasi strategi sehingga rumah sakit tetap dapat melakukan pelayanan dengan baik dan bahkan lebih menguntungkan untuk menghadapi pemberlakuan BPJS Kesehatan oleh pemerintah.

\section{Metodologi Penulisan}

- Jenis dan periode penulisan

Menurut jenis data, jenis penulisan yang digunakan penulis adalah penulisan kualitatif. Dimaksudkan untuk memperoleh ilmu-ilmu lunak yang esensinya sebagai sebuah metode pemahaman atas suatu keunikan dan dinamika lingkungan, sehingga penulisan bersifat luas dan kompleks. Oleh karena itu, temuan dalam studi kualitatif sangat dipengaruhi oleh nilai dan persepsi penulis (Umar, 2013).

- Sumber dan Pengumpulan Data

Data-data yang akan ditampilkan pada penulisan ini adalah berupa :

$>$ Data Primer

Data primer merupakan data yang didapat dari sumber pertama baik dari individu atau perseorangan (Umar, 2013). Dan data primer yang didapat pada penulisan ini didapat langsung dari Rumah Sakit yaitu, Profil Rumah Sakit, Gambaran umum Rumah Sakit, Struktur organisasi Rumah Sakit, Deskripsi faktorfaktor internal dan eksternal Rumah Sakit.

$>$ Data Sekunder

Data sekunder adalah data yang diperoleh melalui study literatur, serta mencari data-data tambahan melalui internet. Data sekunder ini dikumpulkan dan dilakukan dengan tujuan agar mendapat teori dan informasi yang relevan terhadap bahasan penulisan di penulisan ini.

$>$ Data Internal

Data internal merupakan data yang didapat dari dalam perusahaan atau organisasi dimana riset dilakukan (Umar, 2013). Penelitian disini meliputi:

- Observasi :

Kegiatan observasi yang dilakukan adalah dengan cara melakukan pengamatan pada proses bisnis yang terjadi dalam rumah sakit yang berkaitan dengan pelayanan kesehatan kepada pasien serta semua departemen bagian yang ada didalam struktur organisasi rumah sakit.

- Wawancara : 
Wawancara yang dilakukan dalam penulisan ini dilakukan kepada petugas yang berwenang dalam proses persiapan Rumah Sakit Puri Mandiri Kedoya dalam mempersiapkan masuknya BPJS Kesehatan yaitu dr. Melani Sidartha.

Metode Analisa

Data-data tersebut akan diolah dengan menggunakan metode sebagai berikut: Pembahasan Teori Pendukung, Penyajian Data Rumah Sakit, Penyajian Data BPJS Kesehatan.

$>$ Evaluasi Strategi yang Sebaiknya Digunakan

Evaluasi strategi yang digunakan dalam penulisan ini adalah dengan matrix SWOT yaitu dengan analisa SWOT. Matrix ini memaparkan strategi-strategi secara umum yang dapat digunakan oleh Rumah Sakit Puri Mandiri Kedoya untuk menerapkan strategi tersebut dalam proses bisnis rumah sakit, dengan jalan memanfaatkan kekuatan dan peluang serta meminimalisasi kelemahan dan ancaman terhadap Rumah Sakit.

\section{Hasil dan Kesimpulan}

Berdasarkan penelitian yang telah dilakukan oleh penulis, maka simpulan yang dapat diambil dari hasil penelitian meliputi: Dari hasil analisa baik dari analisa faktor internal maupun analisa eksternal rumah sakit puri mandiri kedoya, yaitu dengan menggabungkan antara kekuatan dan ancaman dari rumah sakit puri mandiri kedoya dengan memilih pemasok yang efisien untuk inventory, berkolaborasi dengan manajeman dan staff medis mengenai pemakaian obat-obatan dan alat kesehatan pelayanan, mengefisiensi waktu pelayanan dengan penggunaan dokumentasi medis yang terintegrasi dengan sistem komputerisasi. Menjalin kerjasama rujuk parsial antar RS sekitar. Mengefisiensikan sistem tarif RS dalam menyusun penghitungan subsidi silang untuk mencegah net loss dengan bergabunganya rumah sakit puri mandiri kedoya dengan program pemerintah melalui BPJS Kesehatan rumah sakit tetap dapat bertahan dalam proses pelayanannya.

\section{DAFTAR PUSTAKA}

Aida, Mus. (2013). Mengelola Rumah Sakit Menyesuaikan SJSN Kesehatan. Seminar Nasional. Yogyakarta.

Akdon. (2011). Strategic Management. Bandung : Alfabeta.

Buku Pegangan Sosilalisasi Jaminan Kesehatan Nasional dalam Sistem Jaminan Sosial Nasional. (2013). Jakarta.

Diakses pada 24Agustus

2017,https://inforiau.co/news/detail/7348/gara-gara-bpjs,-rumah-sakit-dan-klinik-terancamtutup.html

Diakses pada 10 Oktober 2017, https://bpjs-kesehatan.go.id/bpjs/

http://hukor.depkes.go.id/uploads/produk_hukum/PMK\%20No.\%2019\%20Th\%202014\%20tt

g\%20Penggunaan\%20Dana\%20Kapitasi\%20JKN.pdf

Hadari, Nawawi. (2005). Manjemen Strategi. Yogyakarta

Hariadi, Bambang. (2005). Strategi Manajemen. Jakarta : Bayumedia Publishing.

Kristianti, Rina. (2017). Manajemen Strategi. Tangerang. Pustaka Mandiri.

Lawrence, Jauch. (1989). Manajemen \& Strategis Kebijakan Perusahaan. Jakarta : Erlangga.

Laksono Trisnantoro (2005), Aspek strategis dalam Manajemen Rumah Sakit. Cetakan pertama. Yogyakarta: Penerbit Andi.

Nasution, Radjab. (2014). Peran Rumah Sakit Swasta sebagai Fasilitas Kesehatan Rujukan dalam Pelayanan Kesehatan di Era Jaminan Kesehatan Nasional. Bandung.

Nilasari, Senja. (2014). Manajemen Strategi itu Gampang. Jakarta: Dunia Cerdas. 
Pearce II, Jhon A. \& Robinson Jr, Richard B.(2013). Manajemen Strategis Formulasi,Implementasi,dan Pengendalian, Buku 1, Edisi 12. Jakarta. Salemba E Rangkuti, F. (2006). Analisis SWOT : Teknik Membedah Kasus Bisnis. Jakarta : Penerbit PT Gramedia Pustaka Utama.

Siagian, Sondang P. (2006). Sistem Informasi Manajemen. Jakarta: PT Bumi Aksara.

Tim Nasional Percepatan Penanggulangan Kemiskinan. (2014). Peran Pemerintah Daerah dalam Implementasi JKN. Jakarta.

Umar, Husein. (2013). Metode Penelitian untuk Skripsi dan Tesis Bisnis. Ed. 2. Jakarta: Rajawali Pers.

Undang-Undang Tentang Sistem Jaminan Sosial Nasional. No. 40 (2004). Jakarta.

Undang-Undang Tentang Badan Penyelenggara Jaminan Sosial. No. 24 (2011). Jakarta Wardani, Iskha. (2016). Formulasi rumah sakit Mayapada Hospital melalui pendekatan analisis SWOT untuk menghadapi diberlakukannya BPJS Kesehatan. 
